Article

\title{
Incidences of Atonic Postpartum Hemorrhage and Related Risk Factors at a Tertiary Hospital in Saudi Arabia
}

\author{
Wedad M. Almutairi $\mathbb{B}$
}

Maternity and Child Department, Faculty of Nursing, King Abdulaziz University, Jeddah 21551, Saudi Arabia; walmutairi@kau.edu.sa

Received: 24 October 2020; Accepted: 30 November 2020; Published: 16 December 2020

\begin{abstract}
Background: In 2017, there were 295,000 maternal deaths worldwide from preventable causes related to birth. The leading cause of maternal mortality is obstetric hemorrhage. In Saudi Arabia, a paucity of evidence about incidences of atonic Postpartum Hemorrhage (PPH) and related risk factors exists. Therefore, aims were to (a) identify incidences of atonic PPH from 2015 to 2018 (b) determine risk factors of atonic PPH in vaginal birth. Methods: Retrospective chart review with purposive sampling conducted revealed 386 charts, 220 (57\%) vaginal birth and 166 (43\%) caesarian section (CS). Logistic regression analysis was used. Results: Incidences of atonic PPH were $2.5 \%$ from 2015 to 2017, with the rate increasing by $12 \%$ from 2017 to 2018. In vaginal birth, significant associations between the severity of blood loss with epidural $(\mathrm{F}=6.314, \mathrm{df}=1, p=0.013)$, episiotomy $(\mathrm{F}=4.38$, $\mathrm{df}=1, p=0.038)$, induction of labor (IOL) $(\mathrm{F}=1.224, \mathrm{df}=1, p=0.004)$, and Interaction between IOL, AUG, and epidural ( $\mathrm{F}=7.24, \mathrm{df}=1, p=0.041)$ found. Discussion: Increasing rate of atonic PPH confirmed. Epidural, episiotomy, induction of labor, and induction with augmentation are factors associated with severe atonic $\mathrm{PPH}$ in vaginal birth.
\end{abstract}

Keywords: PPH; atonic PPH; risk factors; Saudi Arabia

\section{Introduction}

An estimated 295,000 maternal deaths occurred worldwide in 2017, with 211 maternal deaths per 100,000 live births. The lifetime risk of maternal mortality is estimated at one in 190 births, the deaths in low-resource countries being 40 times higher than developed countries [1]. Every day in 2017, 810 women died from preventable causes related to pregnancy and birth [2]. Therefore, target 3.1 of the Sustainable Development Goals (SDG) of the United Nations is to reduce global maternal mortality rate (MMR) to less than 70 in 100,000 by 2030 [2] and to reduce the baseline rate of 2010 to $70 \%$ by 2030 [1]. Based on a 2017 World Health Organization (WHO) report, Saudi Arabia had an MMR of approximately 17\%, and the reduction rate between 2000 and 2017 was only $29 \%$. WHO, along with many organizations and international programs related to maternal health support, list strategies for ending preventable MM. One of the strategies is to determine the related causes of maternal death worldwide [1].

The leading cause of MM is obstetric hemorrhage [1]. Obstetric hemorrhage accounts for $27.1 \%$ of all maternal death worldwide [3]. Of all obstetric hemorrhages, postpartum hemorrhage (PPH) accounts for 72\% [3]. Remarkably, PPH rates are rising worldwide [4-6]. Therefore, an important step to save mothers' lives is to identify the magnitude of the $\mathrm{PPH}$ problem in each country by updating the evidence regarding incidences and causes of PPH in each country.

PPH is traditionally defined as blood loss greater than $500 \mathrm{~mL}$ in vaginal birth and greater than $1000 \mathrm{~mL}$ in caesarian section (CS) birth [7,8]. Primary PPH is defined as "bleeding from the genital tract of $500 \mathrm{~mL}$ or more in the first $24 \mathrm{~h}$ following delivery of the baby" [9]. In 2017, the American College of 
Obstetricians and Gynecologists defined PPH as cumulative blood loss $\geq 1000 \mathrm{~mL}$ or bleeding associated with signs/symptoms of hypovolemia within $24 \mathrm{~h}$ of the birth process regardless of delivery route [10]. Incidences of PPH have increased since 1994 even with medical preventive measures [10]. The factor most responsible for the high prevalence and increasing rate of $\mathrm{PPH}$ is uterine atony, that is, the failure of the uterus to contract efficiently after placenta delivery, accounting for more than $80 \%$ of PPH cases [11,12].

The associated risk factors of the primary atonic PPH are the following: multiple pregnancy, obesity (BMI > 30), advanced maternal age, first birth (nulliparity), history of $\mathrm{PPH}$, and anemia. Risk factors related to pregnancy and the birthing process include gestational age, instrumental delivery, induction and augmentation of labor, prolonged labor (12 to $<24 \mathrm{~h}$ ), uterotonic use, macrosomia (large newborns), laceration, delivery by CS, and vaginal birth after CS $[10,13]$.

WHO reports feature general statistics about trends in obstetric hemorrhage without concise information about incidences of PPH, causes, and the risk factors in each country. This offers a vital opportunity for researchers to investigate the incidences and causes of PPH in their populations. In Saudi Arabia, there is a paucity of evidence regarding incidences of the primary atonic PPH and its related risk factors. Therefore, the aim of this study is to (a) identify incidences of atonic PPH from 2012 to 2018 at a tertiary hospital in Jeddah, Saudi Arabia, and (b) determine the association of the severity of blood loss in atonic PPH women with the following risk factors: maternal age, history of CS, gestational age, birth weight (newborn weight), maternal body mass index (BMI), parity (number of pregnancies), episiotomy, induction of labor (IOL), and augmentation of labor (AUG).

\section{Methods}

We conducted a retrospective chart review study for women who delivered between January 2015 and December 2018 in a tertiary hospital in Jeddah, Saudi Arabia, with selected cases of atonic PPH. We defined cases as women with diagnoses of atonic PPH (International Classification of Disease ICD 10 code O721) chosen from hospital discharge records. Due to the inadequate adoption of ICD coding in the hospital, we also included the charts of women with documented estimated blood loss $>500 \mathrm{~mL}$ in SVD and $>1000 \mathrm{~mL}$ in CS, excluding placental complications, coagulation dysfunction, uterine rupture in the labor and deliver registry book to ensure full access to the primary atonic PPH cases.

Information about the maternal characteristics, obstetric history, pregnancy, labor, and delivery was extracted from the medical records. Expert medical record abstractors used data collection sheets for each case, and inter-rater reliability was applied before data entry to SPSS software. The response variable was amount of blood loss in $\mathrm{ml}$, while the continuous independent variables were age in years, BMI values, parity, gestational age, hemoglobin level at the time of birth, and birth weight. The categorical variables were having an epidural, episiotomy, IOL, and AUG.

Institutional review Board (IRB) approval was obtained (Approved by National Committee of Bio. \& Med. Ethics with reference No 130-18). The study took into consideration ethical principles for conducting research, which includes beneficence, respect for human dignity, and justice. Because the study is a retrospective chart review study that used preexisting data, not all aspects of human subject protection may apply.

For analysis, we used descriptive statistics of number and percentage for reporting incidences of atonic PPH and for identifying the categorical study variables along with mean, median, and standard deviation to describe the continuous variables.

Regarding statistical inference, we categorized the amount of the blood loss in women who had atonic PPH during vaginal delivery into mild $(500-1000 \mathrm{~mL})$ and severe $(>1000 \mathrm{~mL})$ for the purpose of the study. Chi-square is used to determine the relationship between the severity amount of the blood loss and associated variables while the ordinal logistic regression model used to determine the risk factors associated with severity of blood loss in vaginal delivery. The null hypothesis measured the severity of blood loss with associated pairwise comparison, and the alternative hypothesis was blood loss with pairwise independent collection.

We used SPSS software (IBM, Chicago, IL, USA) to execute an ordinal logistic regression model. Blood loss (mild and severe) was used as outcome variable, and all others were independent variables. 
The regression model used the following equation: Blood Loss in Vaginal Birth $=$ Age + Parity + Gestational Age + BMI + Epidural + Episiotomy + Iron Deficiency + IOL + AUG + Hemoglobin Level + Birth Weight.

\section{Results}

Of the 15,483 deliveries documented in the hospital data base, a total of $386(2.5 \%)$ were atonic PPH. The total increasing rate from 2015 to 2018 was 1.87\%. The increasing rate from 2016 to 2017 was $12.7 \%$, and 2017 to 2018 was $14 \%$ Table 1 . Out of the total atonic PPH cases, 220 (57\%) cases were vaginal birth and $166(43 \%)$ were CS birth.

Table 1. Description of the number of atonic postpartum hemorrhage (PPH) cases per year.

\begin{tabular}{cccc}
\hline Year & Number of Total Deliveries & Frequancy of Atonic PPH Each Year & Perecentage \% \\
\hline 2015 & 3553 & 92 & 2.6 \\
\hline 2016 & 3997 & 87 & 2.2 \\
\hline 2017 & 4321 & 106 & 2.5 \\
\hline 2018 & 3612 & 101 & 2.8 \\
\hline Total & 15,483 & 386 & \\
\hline
\end{tabular}

Table 2 represents the total sample characteristics in regards to age, gestational age, BMI, and hemoglobin level at the last antenatal visit. The mean of the estimated blood loss for the total study sample was $1096.54 \mathrm{~mL}$ with a median of $1000 \mathrm{~mL}(\mathrm{SD}=722.53 \mathrm{~mL})$. Out of the total sample, $125(32.4 \%)$ had a history of CS, with 372 (96.4\%) of the participants receiving a total of 20 units of Pitocin (to enhance uterine contractility).

Table 2. Total Sample Characteristics.

\begin{tabular}{cccccc}
\hline & Age & GA * & Birth Wt. & BMI & Hemoglobin \\
\hline$N$ & 386 & 366 & 385 & 383 & 386 \\
\hline Missing & 0 & 20 & 1 & 3 & 0 \\
\hline Mean & 30.62 & 37.69 & 3.00 & 29.84 & 9.62 \\
\hline Std. Deviation & 6.34 & 3.62 & 0.77 & 5.75 & 3.73 \\
\hline \multicolumn{5}{c}{ * GA= Gestational Age. }
\end{tabular}

Table 3 represents the characteristics of women who had a PPH diagnosis during vaginal birth. The average estimated amount of blood loss was $882.29 \mathrm{~mL}$, with a median of $700 \mathrm{~mL}(\mathrm{SD}=576.85 \mathrm{~mL})$. The majority of the participants received a total of 20 units of Pitocin during labor. Regarding episiotomy, 70 (31.8\%) participants presented with episiotomy while only $9(4.1 \%)$ experienced third or fourth perineal tears. Out of the total $220 \mathrm{PPH}$ women, 67 (30.5\%) were primipara (first pregnancy), $54(24.5 \%)$ women were in their second pregnancy, 27 (12.3\%) participants had IOL, and 41 (18.6\%) had AUG. In all vaginal birth participants, the placenta was delivered spontaneously; only 21 (9.5\%) had epidural anesthesia. None of the sample were exposed to instrumental birth.

Table 3. Vaginal Birth Sample Characteristics.

\begin{tabular}{cccccc}
\hline & Age & GA * & Birth Wt. & BMI & Hemoglobin \\
\hline$N$ & 220 & 205 & 220 & 217 & 220 \\
\hline Missing & 0 & 15 & 0 & 3 & 0 \\
\hline Mean & 28.90 & 38.36 & 3.11 & 29.15 & 9.57 \\
\hline Std. Deviation & 6.51 & 3.44 & 0.68 & 5.44 & 1.71 \\
\hline \multicolumn{7}{r}{ *GA Gestational Age. }
\end{tabular}


Table 4 lists the association of each predictor with the response variable blood loss using a chi-square test. Findings revealed significate association between the severity of blood loss and epidural $(p=0.013)$, episiotomy $(p=0.038)$, IOL * epidural $(p=0.004)$, interaction of IOL * AUG * Epidural $(p=0.008)$ with insignificant association $>0.05$ with age, parity, gestational age, BMI, hemoglobin level, Iron Deficiency anemia, and birth weight.

Table 4. Relationship between Dependent (severity of atonic PPH) and Independent Variables.

\begin{tabular}{ccc}
\hline Blood Loss & VS & $p$-Value \\
\hline & Age & 0.945 \\
\cline { 2 - 3 } & Parity & 0.727 \\
\cline { 2 - 3 } & Gestational Age & 0.153 \\
\cline { 2 - 3 } BMI & 0.142 \\
\cline { 2 - 3 } Epidural & 0.013 \\
\cline { 2 - 3 } Iron Deficiency anemia & 0.038 \\
IOL & 0.627 \\
\hline IOL AUG * Epidural & 0.004 \\
\hline Hemoglobin Level & 0.008 \\
\hline B associated at 5\%. & 0.347 \\
\hline
\end{tabular}

The findings showed significant association between blood loss and the epidural $(\mathrm{F}=6.314$, $\mathrm{df}=1, p=0.013)$, episiotomy $(\mathrm{F}=4.38, \mathrm{df}=1, p=0.038)$, and $\mathrm{IOL}(\mathrm{F}=1.224, \mathrm{df}=1, p=0.004)$. The interaction between IOL, AUG, and an epidural on blood loss was significantly associated with the severity of atonic PPH $(\mathrm{F}=7.24, \mathrm{df}=1, p=0.041)$. Age, parity, gestational age, BMI, iron deficiency, hemoglobin level, and birth weight had $p$-values that exceeded 0.05 , which reflected insignificant association with the amount of blood loss during vaginal birth Table 5 .

Table 5. Ordinal Logistic Regression Blood Loss as Dependent Variable.

\begin{tabular}{ccccc}
\hline Variable & F & df & $p$ & Adj. R \\
\hline Age & 0.005 & 1 & 0.945 & 0.190 \\
\hline Parity & 0.123 & 1 & 0.727 & 0.001 \\
\hline Gestational Age & 2.058 & 1 & 0.153 & 0.012 \\
\hline BMI & 2.178 & 1 & 0.142 & 0.013 \\
\hline Epidural * & 6.314 & 1 & 0.013 & 0.190 \\
\hline Episiotomy * & 4.375 & 1 & 0.038 & 0.048 \\
\hline Iron Deficiency & 0.236 & 1 & 0.627 & 0.036 \\
\hline IOL * & 1.224 & 1 & 0.004 & 0.048 \\
\hline $\begin{array}{c}\text { IOL * AUG * } \\
\text { Epidural * }\end{array}$ & 7.236 & 1 & 0.008 & 0.041 \\
\hline Hemoglobin Level & 0.891 & 1 & 0.347 & 0.005 \\
\hline Birth Weight & 0.061 & 1 & 0.806 & 0.190 \\
\hline & $*$ significant at $<0.05$. & &
\end{tabular}




\section{Discussion}

The findings of the study revealed a $2.5 \%$ incidence rate of atonic $\mathrm{PPH}$ in a tertiary hospital in Jeddah, Saudi Arabia. In addition, the findings showed a 1.8\% increase in the rate of atonic PPH from 2015 to 2018, which is comparable with other studies in many countries that report increasing in the incidences of atonic PPH [14-16]. Mehrabadi et al. showed the rate increasing by 33\% in British Columbia, while in Ireland the rate increased from 1\% in 1999 to 3.4\% in 2009 [15]. The increasing rate in the study sample was lower than the rate in British Colombia which could be explained by our study's smaller sample size and one setting for our data collection. Moreover, as a university hospital not the whole population would have access to its care, only people who are working in academia, students, and university employees which limits population variation. Studies also showed repeated increasing rates each year except from 2015 to 2016 which showed a slight drop in the incidence of atonic PPH, this would be explained by the new policy that has been implemented: "baby friendly hospital". However, the incidences returned to increase from 2016 to 2018 which is considered to align with other studies' increasing rates [14,15]. The continuity of the increasing rate since 2016 could have many possible explanations, such an as increasing rate of CS at the study setting, an intensive use of medical interventions during the normal birthing process such as artificial rupture of membranes, higher dose of uterotonic medications [16-20]. Additionally, the ethnic background may be one of the explanations, as in the 2018 births around 9.1\% of the sample were Yemeni; we did not report the nationality in our study because more than $60 \%$ of the sample were Saudi, however ethnic background could be one of the possible reasons [12].

Our analysis revealed that episiotomy is associated with increased severity of atonic $\mathrm{PPH}$; women who had episiotomies were at higher risk of bleeding. This finding confirmed the results of earlier studies conducted in Spain and Saudi Arabia, which found that spontaneous perineal trauma or episiotomy is a risk factor for increasing PPH [21-23]. Additionally, 31\% of the study sample had an episiotomy procedure, comparable to the 35\% incidence rate of performing episiotomies in a tertiary hospital in Saudi Arabia [19]. Episiotomy is a common obstetric intervention in Saudi hospitals, and national efforts are required to reduce the procedure rate with rigorous follow-up to minimize complications [24,25].

Moreover, the study findings revealed a significant association between the severity of atonic PPH and IOL and AUG. Similarly, Ekin et al. (2015) showed a significant association of severe PPH and AUG, [21], and Sheldon et al. found significant association between severe atonic PPH and IOL [9]. Oxytocin is the most common medication used to induce and augment labor [26]. Additionally, Oxytocin is prescribed as an active management of the third stage of labor, with a recommend dosage of $10 \mathrm{IU}$ [27]. However, several studies revealed a direct relationship between the amount of oxytocin administered and the incidences and severity of the atonic PPH [10,16-19]. This explains why women who undergo IOL and AUG using oxytocin have a higher risk of severe atonic PPH. This is due to exposure to a large amount of oxytocin compared to women who did not receive IOL or AUG, which is evident in the significant association of the interaction of induction and augmentation with severity of atonic PPH. Therefore, caution must be exercised with women who had IOL, AUG, or both in order to prevent the incidence of atonic PPH or decrease its severity.

Regarding epidurals' effect on the severity of atonic PPH, our findings did show significant association between epidural alone and the severity of atonic PPH, which align with a previous study that stated that epidural is one of the risk factors of atonic PPH [14]. The association between epidural anesthesia and atonic PPH explained by the effects of epidural on the prolongation of the labor which leads to exhaustion of the uterine muscles and ends up with uterine atony. Moreover, the interaction between induction, augmentation, and epidural showed significant association with severe atonic $\mathrm{PPH}$. This finding might be explained by the risk assessment of $\mathrm{PPH}$, which relied on counting the number of risk factors that women had, correlated with the possibility of predicting the severity of atonic PPH $[9,28]$. 
Regarding parity and BMI, our study findings did not find significant association between the severity of atonic PPH and age and parity (number of pregnancies) in our sample; however, the majority of women who had atonic PPH were nulliparity (first pregnancy). In addition, the mean BMI was 29, which constitutes being overweight, according the international BMI index. These observations align with previous studies' findings $[9,16,29,30]$.

Regarding hemoglobin level, even though our analysis did not determine significant association of low hemoglobin level with severity of atonic PPH, the average hemoglobin level in our sample was 9.5, considered an abnormally low level. This observation is comparable with previous studies that have suggested that women with anemia at the time of birth were more likely to experience significant blood loss [9,29].

Our study has several strengths as well as limitations, the important strength being answering the international call reflected in the SDG target 3.1, to reduce global MMR to less than 70 in 100,000 by 2030 and to reduce the baseline rate of 2010 to $70 \%$ by 2030, which could not happen without a detailed investigation of the leading cause of obstetric hemorrhage, PPH. Another strength is being the first study to investigate the incidences and risk factors of atonic PPH in Saudi Arabia that addresses the findings of MMR in Saudi Arabia based on the WHO report in 2017. To ensure access to every case of atonic PPH and minimize the risk of under-reporting cases, we used two methods to access atonic PPH cases charts by using ICD codes, and manually by reviewing the labor and delivery registry books for 4 years back. The limitation of our study is that of any retrospective chart review that relies on previous documentations that might be inaccurate, incomplete and shown variation of healthcare providers documentation. Data about history of previous placental complications, medical history of the patients (e.g., hypertension, Diabetes.) and pregnancy-related complications such as preeclampsia, eclampsia or gestational diabetes were not collected, which may have added more information regarding atonic PPH cases in Saudi Arabia and added more risk factors. Moreover, the documentation of the duration of second and third stage of labor was not clear in the patient file and no clear answer was taken from the nurses in the labor room, so we remove the labor duration variable which added another limitation to the study. In addition, using atonic PPH data from one setting in Saudi Arabia limits the generalization of our findings regarding atonic PPH incidences and risk factors to the Saudi population in which we need to uncover the trends of atonic PPH.

\section{Conclusions}

In conclusion, the incidence of atonic PPH in the total sample was $2.5 \%$, with the rate increasing by 12\% between 2017 and 2018 in a tertiary hospital in Saudi Arabia. Risk factors that increase the severity of atonic PPH are epidural, episiotomy, induction of labor, and induction supplemented with augmentation of labor. Women who had an episiotomy, induction of labor, or augmentation are predicted to have a larger amount of blood loss $(>1000 \mathrm{~mL})$ during vaginal delivery compared to patients who did not receive those procedures. The clinical implications of the study would be the reevaluation of the postpartum hemorrhage risk assessment tool and considering epidural, induction of labor, augmentation of labor, and episiotomy as factors that might increases the risk scores. This will help for the early detection of risky women for severe atonic PPH, which minimizes the adverse effects of the disease and facilitates the early management of it. Future studies are needed regarding the national trends of atonic PPH in Saudi Arabia, with a larger sample size in different settings across the country. This could be national study to ensure a good representation of the Saudi population.

Funding: This research received Funding from Deanship of Scientific Research (DSR) at King Abdulaziz University, Jeddah, Saudi Arabia: J:21-688-1440.

Conflicts of Interest: The author declares no conflict of interest. 


\section{References}

1. World Health Organization. Maternal mortality: Levels and Trends 2000 to 2017. Available online: https://www.who.int/publications/i/item/9789241516488 (accessed on 3 January 2020).

2. United Nations. Goal 3: Ensure Healthy Lives and Promote Well-Being for All at All Ages. Available online: https://www.un.org/sustainabledevelopment/health/ (accessed on 5 January 2020).

3. Say, L.; Chou, D.; Gemmill, A.; Tunçalp, Ö.; Moller, A.-B.; Daniels, J.; Gülmezoglu, A.M.; Temmerman, M.; Alkema, L. Global causes of maternal death: A WHO systematic analysis. Lancet Glob. Health 2014, 2, e323-e333. [CrossRef]

4. Mehrabadi, A.; Liu, S.; Bartholomew, S.; Hutcheon, J.A.; Kramer, M.S.; Liston, R.M.; Joseph, K. Temporal trends in postpartum hemorrhage and severe postpartum hemorrhage in Canada from 2003 to 2010. J. Obstet. Gynaecol. Can. 2014, 36, 21-33. [CrossRef]

5. Van Stralen, G.; Van Roosmalen, J.; Bloemenkamp, K.W.; van Roosmalen, J.; Hukkelhoven, C.W. Increasing incidence of postpartum hemorrhage: The Dutch piece of the puzzle. Acta Obstet. Gynecol. Scand. 2016, 95, 1104-1110. [CrossRef] [PubMed]

6. Maswime, S.; Buchmann, E. A systematic review of maternal near miss and mortality due to postpartum hemorrhage. Int. J. Gynecol. Obstet. 2017, 137, 1-7. [CrossRef] [PubMed]

7. Wormer, K.C.; Jamil, R.T.; Bryant, S.B. Acute Postpartum Hemorrhage. Available online: https://www. statpearls.com/articlelibrary/viewarticle/27638/ (accessed on 23 October 2019).

8. World Health Organization. WHO Recommendations for the Prevention and Treatment of Postpartum Haemorrhage. Available online: http://www.who.int/reproductivehealth/publications/maternal_perinatal_ health/9789241548502/en/ (accessed on 23 October 2019).

9. Sheldon, W.R.; Blum, J.; Vogel, J.P.; Souza, J.P.; Gülmezoglu, A.M.; Winikoff, B.; On behalf of the WHO Multicountry Survey on Maternal and Newborn Health Research Network. Postpartum haemorrhage management, risks, and maternal outcomes: Findings from the World Health Organization multicountry survey on maternal and newborn health. BJOG 2014, 121 (Suppl. 1), 5-13. [CrossRef] [PubMed]

10. Committee on Practice Bulletins-Obstetrics. Practice Bulletin No. 183: Postpartum Hemorrhage. Obstet. Gynecol. 2017, 130, e168-e186. [CrossRef] [PubMed]

11. Lisonkova, S.; Mehrabadi, A.; Allen, V.M.; Bujold, E.; Crane, J.M.; Gaudet, L.; Gratton, R.J.; Ladhani, N.N.N.; Olatunbosun, O.A.; Joseph, K.S. Atonic postpartum hemorrhage: Blood loss, risk factors, and third stage management. J. Obstet. Gynaecol. Can. 2016, 38, 1081-1090.e2. [CrossRef]

12. Ngwenya, S. Postpartum hemorrhage: Incidence, risk factors, and outcomes in a low-resource setting. Int. J. Women's Health 2016, 8, 647-650. [CrossRef]

13. Nyfløt, L.T.; Sandven, I.; Stray-Pedersen, B.; Pettersen, S.; Al-Zirqi, I.; Rosenberg, M.; Jacobsen, A.F.; Vangen, S. Risk factors for severe postpartum hemorrhage: A case-control study. BMC Pregnancy Childbirth 2017, 17, 17. [CrossRef]

14. Davey, M.A.; Flood, M.; Pollock, W.; Cullinane, F.; McDonald, S. Risk factors for severe postpartum haemorrhage: A population-based retrospective cohort study. Aust. N. Z. J. Obstet. Gynaecol. 2019, 60, 532-533. [CrossRef]

15. Knight, M.; Callaghan, W.M.; Berg, C.; Alexander, S.; Bouvier-Colle, M.-H.; Ford, J.B.; Joseph, K.S.; Lewis, G.; Liston, R.M.; Roberts, C.L.; et al. Trends in postpartum hemorrhage in high resource countries: A review and recommendations from the International Postpartum Hemorrhage Collaborative Group. BMC Pregnancy Childbirth 2009, 9, 55. [CrossRef] [PubMed]

16. Hidalgo-Lopezosa, P.; Hidalgo-Maestre, M.; Rodríguez-Borrego, M.A. Labor stimulation with oxytocin: Effects on obstetrical and neonatal outcomes. Rev. Atino-Am. Enferm. 2016, 24, e2744. [CrossRef] [PubMed]

17. Driessen, M.; Bouvier-Colle, M.-H.; Dupont, C.; Khoshnood, B.; Rudigoz, R.-C.; Deneux-Tharaux, C. Postpartum hemorrhage resulting from uterine atony after vaginal delivery: Factors associated with severity. Obstet. Gynecol. 2011, 117, 21-31. [CrossRef] [PubMed]

18. Frolova, A.I.; Raghuraman, N.; Woolfolk, C.L.; López, J.D.; Macones, G.A.; Cahill, A.G. 303: Effect of oxytocin maximum dose and duration of exposure on postpartum hemorrhage following vaginal delivery. Am. J. Obstet. Gynecol. 2019, 220, S213-S214. [CrossRef] 
19. Grotegut, C.A.; Paglia, M.J.; Johnson, L.N.C.; Thames, B.; James, A.H. Oxytocin exposure during labor among women with postpartum hemorrhage secondary to uterine atony. Am. J. Obstet. Gynecol. 2011, 204, E1-E56. [CrossRef] [PubMed]

20. Lutomski, J.E.; Byrne, B.M.; Devane, D.; Greene, R.A. Increasing trends in atonic postpartum haemorrhage in Ireland: An 11-year population-based cohort study. BJOG 2012, 119, 306-314. [CrossRef] [PubMed]

21. Mehrabadi, A.; Hutcheon, J.A.; Lee, L.; Kramer, M.S.; Liston, R.M.; Joseph, K.S. Epidemiological investigation of a temporal increase in atonic postpartum haemorrhage: A population-based retrospective cohort study. BJOG 2013, 120, 853-862. [CrossRef] [PubMed]

22. Al-Kadri, H.M.; Tariq, S.; Tamim, H.M. Risk factors for post-partum hemorrhage among Saudi women. Saudi Med. J. 2009, 30, 1305-1310. [PubMed]

23. Rubio-Alvarez, A.; Molina-Alarcon, M.; Hernandez-Martinez, A. Relationship between the degree of perineal trauma at vaginal birth and change in haemoglobin concentration. Women Birth 2017, 30, 382-388. [CrossRef] [PubMed]

24. Oraif, A. Routine episiotomy practice at a tertiary care center in Saudi Arabia. Open J. Obstet. Gynecol. 2016, 6, 794-797. [CrossRef]

25. Saadia, Z. Rates and indicators for episiotomy in modern obstetrics-a study from Saudi Arabia. Mater. Socio-Med. 2014, 26, 188. [CrossRef] [PubMed]

26. Ekin, A.; Gezer, C.; Solmaz, U.; Taner, C.E.; Dogan, A.; Ozeren, M. Predictors of severity in primary postpartum hemorrhage. Arch. Gynecol. Obstet. 2015, 292, 1247-1254. [CrossRef] [PubMed]

27. WHO. WHO Recommendations: Intrapartum Care for a Positive Childbirth Experience; World Health Organization: Geneva, Switzerland, 2018; License: CC BY-NC-SA 3.0 IGO.

28. Kawakita, T.; Mokhtari, N.; Huang, J.C.; Landy, H.J. Evaluation of risk-assessment tools for severe postpartum hemorrhage in women undergoing cesarean delivery. Obstet. Gynecol. 2019, 134, 1308-1316. [CrossRef] [PubMed]

29. Kramer, M.S.; Berg, C.; Abenhaim, H.; Dahhou, M.; Rouleau, J.; Mehrabadi, A.; Joseph, K.S. Incidence, risk factors, and temporal trends in severe post-partum hemorrhage. Am. J. Obstet Gynecol. 2013, 209, 449.e1-7. [CrossRef]

30. Fukami, T.; Koga, H.; Goto, M.; Ando, M.; Matsuoka, S.; Tohyama, A.; Yamamoto, H.; Nakamura, S.; Koyanagi, T.; To, Y.; et al. Incidence and risk factors for postpartum hemorrhage among transvaginal deliveries at a tertiary perinatal medical facility in Japan. PLoS ONE 2019, 14, e0208873. [CrossRef]

Publisher's Note: MDPI stays neutral with regard to jurisdictional claims in published maps and institutional affiliations.

(C) 2020 by the author. Licensee MDPI, Basel, Switzerland. This article is an open access article distributed under the terms and conditions of the Creative Commons Attribution (CC BY) license (http://creativecommons.org/licenses/by/4.0/). 